\title{
Probing smoking craving with a multidimensional approach: validation of the 12-item French-language version of the Questionnaire on Smoking Urges
}

This article was published in the following Dove Press journal:

Neuropsychiatric Disease and Treatment

7 August 2014

Number of times this article has been viewed

\author{
Vincent Dethier' \\ Alexandre Heeren ${ }^{1,2}$ \\ Laurence Galanti ${ }^{3}$ \\ Pierre Philippot ${ }^{1}$ \\ Joël Billieux'
}

'Laboratory for Experimental Psychopathology, Psychological Science Research Institute, Université catholique de Louvain, Louvain-la-

Neuve, Belgium; ${ }^{2}$ National Fund for

Scientific Research, Brussels, Belgium;

${ }^{3}$ Department of Clinical Biology,

Mont-Godinne University Hospital,

Yvoir, Belgium

Correspondence: Vincent Dethier; Joël Billieux

Laboratory for Experimental

Psychopathology, Institute

of Psychological Science, Université

catholique de Louvain, Place du Cardina

Mercier, 10, B-1348 Louvain-la-Neuve,

Belgium

Tel +32 I0 $474 \quad 122$

Fax +32 I0 473774

Email vincent.dethier@uclouvain.be;

joel.billieux@uclouvain.be
Background: The current study examined the psychometric properties of the 12-item French-language version of the Questionnaire on Smoking Urges (QSU-12), a widely used multidimensional measure of cigarette craving.

Methods: Daily smokers ( $\mathrm{n}=230$ ) completed the QSU-12, the Fägerstrom Test for Nicotine Dependence, and items about addiction-related symptoms. Additional participants $(n=40)$ completed the QSU-12 and the Fägerstrom Test for Nicotine Dependence and were assessed for expired carbon monoxide.

Results: Consistent with studies validating the English version of the scale, confirmatory factor analyses supported a two-factor solution in the French version of the scale. Good scale and subscales reliabilities were observed, and convergent validity was evidenced through relationships with dependence and addiction-related symptoms.

Conclusion: The French-language version of the QSU-12 is an adequate instrument to assess the multidimensional construct of craving in both research and clinical practice.

Keywords: tobacco, smoking, nicotine, craving, measurement model, psychometrics, confirmatory factor analyses, carbon monoxide, addiction

\section{Introduction}

Craving is an important part of the experience of people with addiction and is listed as one of the features of psychoactive substance dependence in the International Classification of Diseases ${ }^{1}$ and in the Diagnostic and Statistical Manual of Mental Disorders. ${ }^{2}$ Likewise, dominant biopsychological models of addiction consider craving to play a core role in the maintenance of addiction. ${ }^{3-6}$ At the empirical level, craving is a predictor of smoking relapse, ${ }^{7-9}$ and its decrease contributes to the effectiveness of pharmacological treatments. ${ }^{10,11}$ Hence, craving assessment has considerable utility for diagnosis and clinical outcomes. ${ }^{12}$

There have been numerous definitions of craving. For instance, Tiffany has suggested that craving is a subjective motivational state that encourages compulsive drug self-administration, hinders efforts to achieve abstinence, and causes a relapse following sustained drug abstinence. ${ }^{6}$ While some authors have restricted the meaning of craving to the experience of a strong desire to use a drug, ${ }^{13,14}$ other have proposed conceptions that encompass various affective and cognitive components. Indeed, some have considered the anticipation of the drug's consequences, the intentions to use drugs, mental images, and drug-related affects and cognitions as part of the concept of craving. ${ }^{4,15-17}$ This latter conception highlights the multidimensional nature of craving. 
Over the last two decades, many studies have evaluated craving by using a single item. ${ }^{18-21}$ However, such an approach limits the assessment of reliability and validity, as it restricts craving to an unidimensional construct. ${ }^{12,22}$ Addressing these two flaws, the Questionnaire on Smoking Urges $(\mathrm{QSU})^{17}$ is the most widely used multidimensional measure of craving for cigarettes. The 32-item Englishlanguage version of the questionnaire was originally developed to capture various aspects of craving experiences (ie, desire to smoke, anticipation of positive reinforcement, anticipation of negative reinforcement, intention to smoke). In the initial validation study, exploratory factor analysis revealed a two-factor solution. Whereas one factor was related to the anticipation of relief from negative affect or withdrawal symptoms (negative reinforcement), the other factor was linked to the intention/desire to smoke and to the anticipation of positive outcomes (positive reinforcement). This bifactorial structure has been replicated. ${ }^{23,24}$ Since its creation, the QSU has been translated and validated in several languages, including Spanish, ${ }^{25}$ German, ${ }^{26}$ and French. ${ }^{27}$

Recently, various short versions of the QSU have been developed. Short versions are useful for both research and clinical purposes (given that long scales are rarely incorporated in systematic clinical screening and/or research protocols). A 12-item version (QSU-12) was proposed by Kozlowski et $\mathrm{a}^{28}$ on the basis of the highest loadings. A 10-item version (QSU-10) was then proposed by Cox et $\mathrm{al}^{29}$ on the basis of both factor loadings and content coverage. Moreover, some statements were reworded to avoid reversed items. Validation studies conducted on both the 10 -item and the 12-item versions corroborated a two-factor structure similar to the initial version of the scale. ${ }^{29-33}$ Short versions of the QSU have been translated and validated in various languages: Spanish, ${ }^{25}$ Portuguese,${ }^{34}$ Italian, ${ }^{35}$ and Chinese. ${ }^{36}$

Although this scale has not been validated into French, several studies have already used these short versions among French-speaking samples. ${ }^{37-39}$ However, uncertainty still abounds regarding the psychometric properties, particularly regarding the factor structure of the French short versions of the QSU. In the initial validation of the French long version of the QSU, exploratory factor analysis (EFA) demonstrated a bifactorial structure. ${ }^{27}$ However, there are a number of limitations to EFA, thereby limiting the generalizability of these findings. Indeed, although EFA is a useful approach when there is an insufficient theoretical and empirical basis to specify a model, confirmatory factor analysis (CFA) remains necessary to test a specific hypothesis about the structure of the data and to determine whether a proposed model fits the data well. In the present study, we use the 12-item version because it comprises negatively worded items, as suggested by the recommendations of the international test development. ${ }^{40}$

The aim of the current study was to examine the psychometric and structural properties of the French-language QSU-12. We thus conducted CFA and explored the internal consistency of the scale. An additional sample was recruited in order to evaluate convergent validity with expired carbon monoxide (CO). This measure allowed us to objectively quantify the degree of exposure to one of the major components of tobacco smoke.

\section{Methods \\ Participants}

Participants were French-speaking smokers (daily smokers who had smoked at least 100 cigarettes during their entire life) aged 18 years and older. They were recruited through advertisements posted in French specialized forums and research networks. Participants were invited to circulate the invitational email to their acquaintances (ie, snowball principle emailing). In order to include a maximal number of participants, data were collected via an online survey (subsample 1). The participants of an additional sample (subsample 2) filled in the questionnaires on a written survey. Subsample 2 participants were recruited within the framework of a master's degree thesis and, in accordance with the design of that study, were instructed not to smoke in the hour prior to the data collection.

All participants gave their consent before starting the survey. The study protocol was approved by the ethical committee of the Psychology Department of the Université catholique de Louvain.

\section{Instruments}

Participants in subsample 1 were first asked about their tobacco consumption (number of cigarettes per day and time since the last cigarette was smoked). They then completed the French version of the QSU-12. ${ }^{27}$ Each item was completed on a seven-point Likert-type scale from totally disagree (1) to totally agree (7). After completing the QSU-12, participants filled out the French version of the Fagerström Test for Nicotine Dependence (FTND), ${ }^{41}$ which is a six-item self-report questionnaire that is widely used to assess the level of tobacco dependence. Finally, six supplementary 
items were generated to assess 1) negative impact of tobacco smoking on daily living, 2) frequency of smoking behaviors triggered by negative emotional contexts, 3) frequency of smoking behaviors triggered by positive emotional contexts, 4) frequency of smoking behaviors associated with pleasure or excitement seeking, 5) loss of control associated with smoking, and 6) frequency of intrusive thoughts or mental images related to smoking. These items were scored using a four-point Likert scale.

The participants in the subsample 2 were first measured for expired $\mathrm{CO}$ with the Micro Smokerlyzer ${ }^{\circledR}$ (Bedfont Scientific Ltd, Kent, UK), after which they completed questions about their tobacco consumption, the QSU-12, and the FTND. CO is a biological marker of exposure to combustion byproducts via inhalation. When tobacco is ignited and inhaled, $\mathrm{CO}$ is produced and binds to hemoglobin to form carboxyhemoglobin before being expired into the air. The half-life of $\mathrm{CO}$ is $2-5$ hours and it is expressed in parts per million. ${ }^{42}$

\section{Data analysis}

CFA were performed using SPSS AMOS $16^{\circledR}$ (IBM Corporation, Armonk, NY, USA). Three models were tested: Model A, a single-factor solution as suggested by Kozlowski et al; ${ }^{28}$ Model B, a correlated two-factor solution as suggested by factor analysis on the French version of the QSU; ${ }^{27}$ and Model C, a correlated two-factor solution derived from the English versions of the QSU. ${ }^{17,33}$ It should be noted that Model B and Model C differ for only one item, in that item 9 of the scale ("I have an urge for a cigarette") loads on the relief of negative affect dimension (Factor 1) in Model $\mathrm{B}$ and loads on the intention and desire to smoke dimension (Factor 2) in Model C. Moreover, internal consistency and convergent validity were also evaluated.

Before performing the analysis, we conducted the Kolmogorov-Smirnov test on each item of the QSU-12. Normality was not achieved for all items $(P<0.0001)$. Moreover, the standard method of estimation in structural equation modeling is maximum likelihood, which assumes multivariate normality of manifest variables. As noted by Byrne, ${ }^{43}$ a frequent error when performing CFA is that the normality of the data is not taken into account multivariately. In our case, multivariate kurtosis was indeed high, with a Mardia's coefficient ${ }^{44}$ of 58.172 (with a cut-off value of 26.073), indicating a lack of multivariate normality. The items of the QSU-12 refer to a sample of psychological constructs that can be present or absent with varying frequency. This makes nonnormality and categorization problems likely. ${ }^{45,46}$ Therefore, using standard normal theory estimators with these data could produce estimation problems.

Various formulas can be applied to correct for the lack of multivariate normality when performing CFA. The most appropriate approach is to use an estimation method that makes no distributional assumptions, such as the unweighted least squares (ULS) estimation method. ULS is analogous to ordinary least squares in traditional regression.

Because the covariance matrix might not be as asymptotically distributed as chi-square with the ULS method, the chi-square test and other fit indexes based on such statistics cannot be computed and are thus not reported. ${ }^{47}$ Instead, we used the following fit indices: 1) Goodness-of-Fit Index (GFI), 2) Adjusted Goodness-of-Fit Index (AGFI), 3) Parsimony Goodness-of-Fit Index (PGFI), and 4) Parsimony Ratio (PRATIO). Incremental and residual fit indices cannot be used with the ULS method. ${ }^{47}$

GFI is an absolute-fit index with a corresponding adjusted version, the AGFI, developed to incorporate a penalty function for the addition of free parameters in the model. ${ }^{48}$ The GFI is analogous to $R^{2}$ and performs better than any other absolute-fit index regarding the absolute fit of the data ${ }^{49,50}$ Both GFI and AGFI have values between $0-1$, with 1 indicating a perfect fit. A value of 0.80 is usually considered as a minimum for model acceptance. ${ }^{51}$

PGFI and PRATIO are parsimony-based fit measures. Absolute fit measures judge the fit of a model per se without reference to other models that could be relevant in the situation. ${ }^{52}$ Parsimony-adjusted measures introduce a penalty for complicating the model by increasing the number of parameters in order to increase the fit. Usually, parsimony-fit indices are much lower than other normed-fit measures. Values larger than 0.60 are generally considered satisfactory..$^{53}$

The present context also requires comparing fit across different models that are not necessarily nested (ie, meaning that one model is not simply a constrained version of the other). Therefore, we also reported the Akaike Information Criterion (AIC), ${ }^{54}$ the Browne-Cudeck Criterion (BCC), ${ }^{55}$ and the Expected Cross-Validation Index (ECVI), ${ }^{55}$ which are the most suited for comparison of nonnested models. ${ }^{53}$ AIC, $\mathrm{BCC}$, and ECVI are fit measures based on information theory. These indices are not used for judging the fit of a single model but are used in situations in which one needs to choose from several realistic but different models. These indices are a function of both model complexity and goodness of fit. For these indices, low scores refer to simple well-fitting models, 
whereas high scores refer to complex poor-fitting models. Therefore, in a comparison-model approach, the model with the lower score is to be preferred.

\section{Results}

In all, 270 participants were enrolled on study. Of these, $230(85.2 \%)$ were recruited for subsample 1 and $40(14.8 \%)$ were recruited for subsample 2 . The characteristics of both subsamples are presented in Table 1.

\section{Structural validity}

Table 2 displays the fit indices of the three models. The three models have very good fit indices. However, Model B exhibited better fit than both Model A and Model C, as indexed by GFI and AGFI. Moreover, the AIC, BCC, and ECVI were strongly favorable to Model B (see Figure 1).

As shown in Figure 1, the standardized factor loadings of Model B were all statistically significant $(P<0.01)$. Three items, however, showed loadings below 0.40 (ie, items 2, 3 , and 8 ). Therefore, we also reran analyses with a new model similar to Model B but without these items. Even if a couple of fit indices tended to be better than those of previous models, this new model did not lead to any significant global improvement $(\mathrm{GFI}=0.984$; $\mathrm{AGFI}=0.972$; $\mathrm{PGFI}=0.569$; PRATIO $=0.722$ ). In order to be consistent with the initial scale, we did not exclude these items. The items are presented in Table $\mathrm{S} 1$.
Descriptive statistics, internal consistency reliability, and external validity

Cronbach $\alpha$ coefficients for both Factor $1(\alpha=0.90$, total score, mean 16.5 \pm 9.9$)$ and Factor $2(\alpha=0.80$, total score, mean 20.8 \pm 8.0 ) were higher than 0.75 , suggesting good scale and subscale reliability. ${ }^{56}$ Table 3 displays the correlations between the QSU-12 subscales and other measures. Both subscales were strongly correlated with the global score. They were also positively and significantly related to cigarette consumption, FTND, loss of control (ie, difficulty in not smoking) and frequency of intrusive thoughts related to smoking behaviors. Moreover, $r$-to-Z Fisher score transformation $^{57}$ indicated that the FTND was significantly more related to Factor 1 than to Factor 2 of the QSU-12 ( $\mathrm{Z}[270]=2.065, P<0.05)$. Moreover, the frequency of intrusive thoughts related to smoking behaviors was more significantly related to Factor 1 than to Factor 2 of the QSU-12 $(Z[230]=2.384, P<0.05)$. Factor 1 was significantly and positively related to the negative impact of tobacco smoking on daily living, to the proneness to smoke in response to negative emotional contexts, and to the number of years of smoking. No other correlation was significant for the dimensions of the QSU-12.

\section{Discussion}

The current study examined the psychometric properties of a French version of the QSU-12. Results showed that the

Table I Participants' characteristics

\begin{tabular}{|c|c|c|c|}
\hline & & $\begin{array}{l}\text { Subsample I } \\
(n=230)\end{array}$ & $\begin{array}{l}\text { Subsample } 2 \\
(n=40)\end{array}$ \\
\hline Age (years), mean (SD) & & $32.3(11.4)$ & $38.9(11.2)$ \\
\hline Female, \% & & 62.6 & 52.5 \\
\hline \multirow[t]{5}{*}{ Highest degree, \% } & University & 62.2 & 20.0 \\
\hline & College & 20.0 & 30.0 \\
\hline & High school & 11.3 & 47.5 \\
\hline & Middle school & 6.1 & 0.0 \\
\hline & Elementary school & 0.4 & 2.5 \\
\hline \multirow[t]{3}{*}{ Nationality, \% } & Belgium & 34.8 & 100.0 \\
\hline & France & 57.4 & 0.0 \\
\hline & Other countries & 7.8 & 0.0 \\
\hline \multirow[t]{6}{*}{ Time elapsed since the last cigarette, $\%$} & $<15$ minutes & 19.6 & 0.0 \\
\hline & $15-30$ minutes & 10.0 & 0.0 \\
\hline & $30-60$ minutes & 13.5 & 0.0 \\
\hline & I-2 hours & 27.5 & 5.0 \\
\hline & $2-4$ hours & 15.7 & 70.0 \\
\hline & $>4$ hours & 15.7 & 25.0 \\
\hline FTND, mean (SD) & & $3.1(2.6)$ & $3.5(2.1)$ \\
\hline Number of cigarettes smoked per day, mean (SD) & & I3.I (10.0) & $14.0(5.8)$ \\
\hline Consume cannabis occasionally, \% & & 12.6 & 0.0 \\
\hline Carbon monoxide (ppm), mean (SD) & & No data & $12.2(5.4)$ \\
\hline
\end{tabular}

Abbreviations: FTND, Fagerström Test for Nicotine Dependence; ppm, parts per million of expired air; SD, standard deviation. 
Table 2 Fit index values for the different tested models

\begin{tabular}{lllllllll}
\hline Model & df & GFI & AGFI & PGFI & PRATIO & AIC & BCC & ECVI \\
\hline A & 54 & 0.970 & 0.957 & 0.671 & 0.818 & 444.892 & 447.330 \\
B & $\mathbf{5 3}$ & $\mathbf{0 . 9 7 8}$ & $\mathbf{0 . 9 6 7}$ & $\mathbf{0 . 6 6 4}$ & $\mathbf{0 . 8 0 3}$ & $\mathbf{3 7 8 . 0 4 9}$ & $\mathbf{3 8 0 . 5 8 9}$ & $\mathbf{1}$ \\
C & 53 & 0.974 & 0.962 & 0.662 & 0.803 & 421.568 & 424.107 & 1.567 \\
\hline
\end{tabular}

Note: We considered Model B (emphasized by bold font) to be the best fitting model.

Abbreviations: AGFI, Adjusted Goodness-of-Fit Index; AIC, Akaike Information Criterion; BCC, Browne-Cudeck Criterion; df, degree of freedom; ECVI, Expected CrossValidation Index; GFI, Goodness-of-Fit Index; PGFI, Parsimony Goodness-of-Fit Index; PRATIO, Parsimony Ratio.

correlated two-factor solution derived from the long French version of the $\mathrm{QSU}^{27}$ best fits the data, in comparison to the single-factor solution suggested by Kozlowski et $\mathrm{al}^{28}$ as well as the correlated two-factor solution derived from the English versions of the scale. ${ }^{17,33}$ The first factor assesses the urgency to smoke to relieve withdrawal and/or negative affect, whereas the second factor assesses the intention and desire to smoke. A good internal consistency was also observed.

In regard to the growing development of short assessment methods for clinical and research use, some methodological guidelines have been proposed to ensure the validity of such abbreviated forms. ${ }^{58}$ One of them highlights the importance of showing that a reduction in the questionnaire constitutes a trade-off between gained assessment time and induced loss of validity. We thus sought to evaluate this trade-off in the present study. On the one hand, assuming that approximately 15 seconds are necessary to fill out one item of the QSU, the completion time of the original 32-item scale is 8 minutes, whereas the short version takes only 3 minutes to complete. On the other hand, we found the QSU-12 to have a similar structure to the original French scale. Moreover, the internal reliability coefficients of the QSU-12 remained satisfactory. Finally, convergent validity was shown through

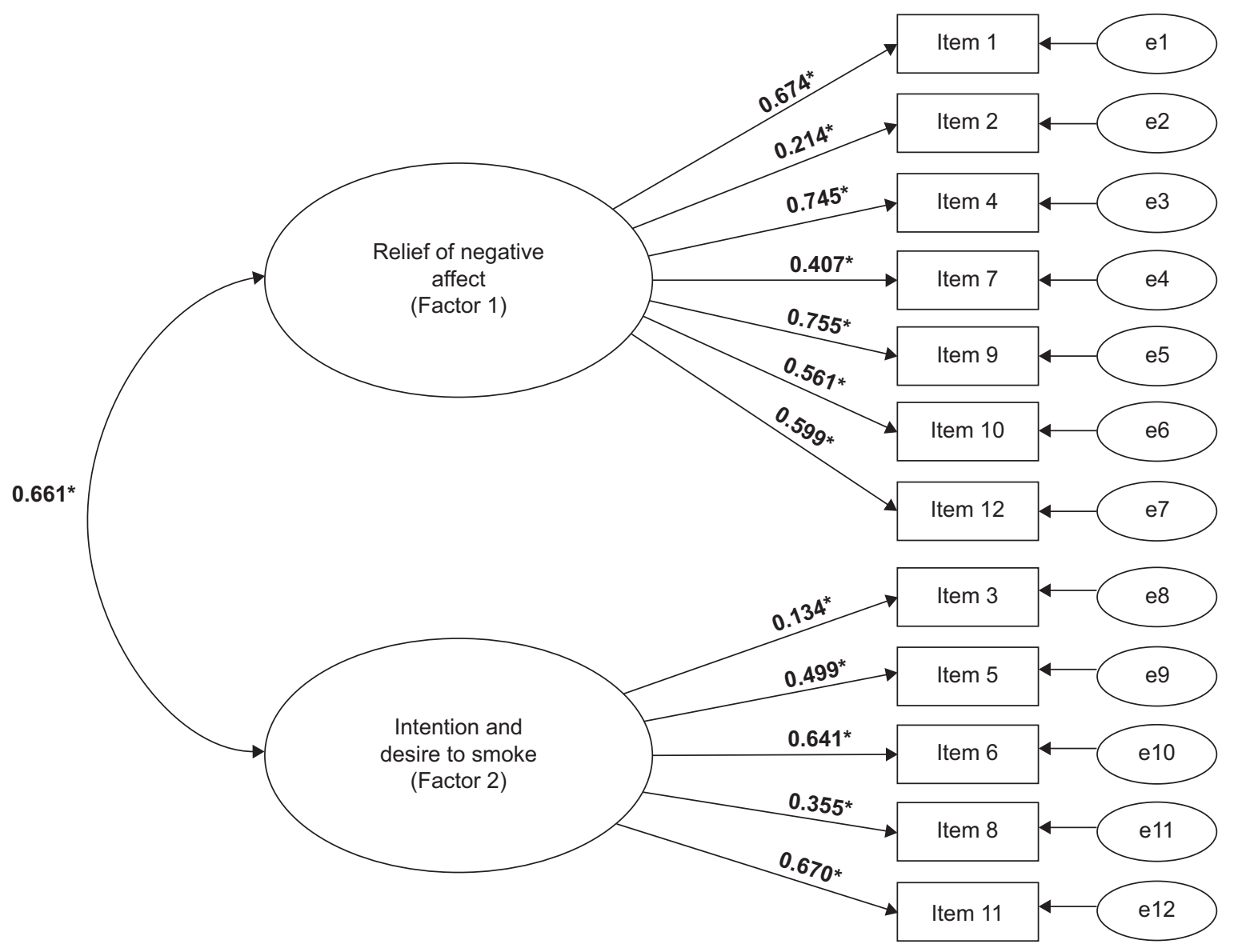

Figure I Path diagram depicting the correlated two-factor solution (Model B) of the short French version of the Questionnaire on Smoking Urges. Notes: $* P<0.01$. For each item, e represents the error measurement related to that specific item. 


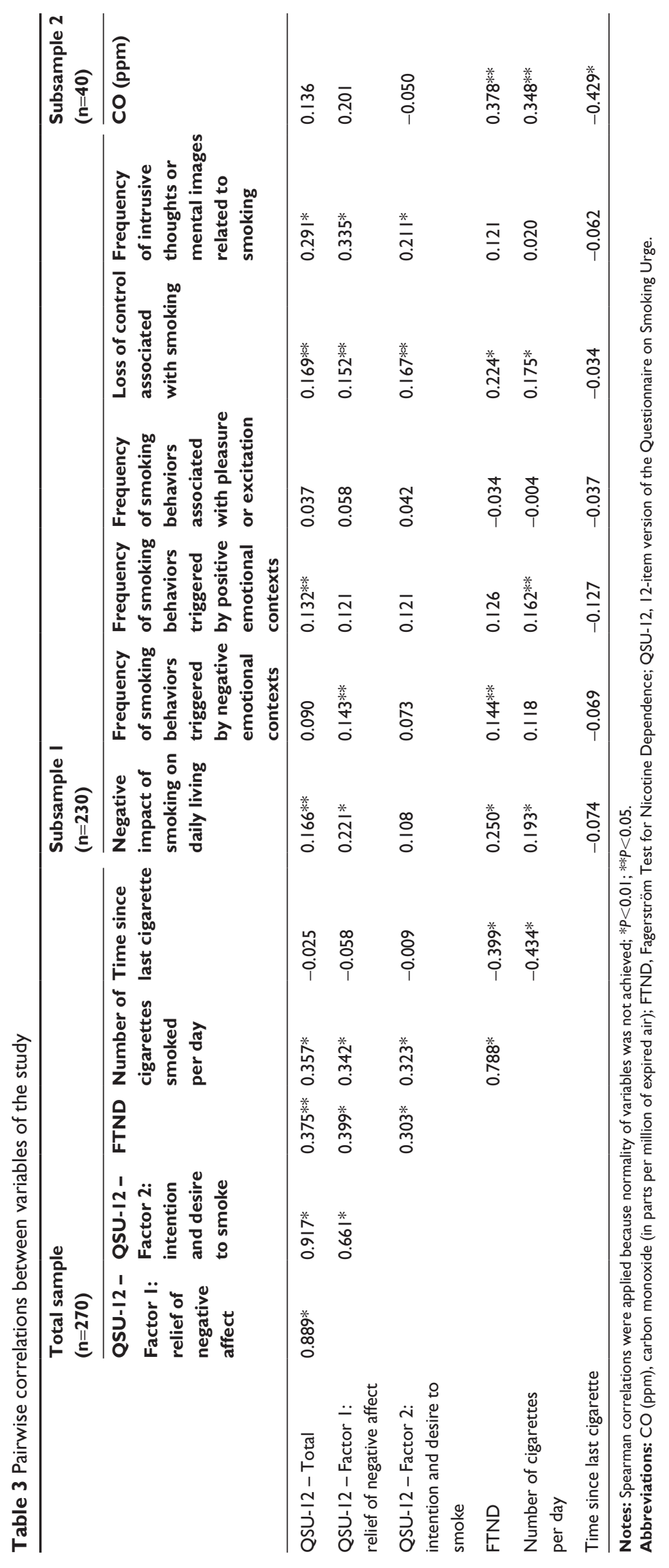


the relationships with both a global scale of tobacco dependence and the items measuring addiction-related symptoms (eg, smoking in affective contexts, loss of control, intrusive thoughts, and adverse consequences in daily life). Taken together, these results support the use of the QSU-12 for a meaningful timesaving.

Relations were observed between the QSU-12 subscales and addiction symptoms. We found a correlation between both factors and loss of control (ie, difficulty in not smoking, more especially for Factor 1). This correlation is consistent with the literature, because craving has been shown to predict smoking lapses. ${ }^{9}$ Both factors were also associated with the frequency of intrusive thoughts or mental images related to smoking. This finding makes sense in view of recent models that consider intrusion and mental images' elaboration as central to craving episodes. ${ }^{4,16}$

Dimensions of craving were related to dependence and to the number of cigarettes smoked per day. However, dimensions of craving were not significantly related to the time since the last cigarette. In the validation of the original version of the QSU, the authors manipulated the time since the last cigarette and found an overall increase of craving for both factors of the QSU from 0-6 hours of abstinence. In the current study, the time since the last cigarette is strongly related to the mean number of cigarettes per day. The absence of correlation should thus be interpreted cautiously, as we did not manipulate it and thus did not capture the distribution of the variables when the individual engaged in a longer abstinence period than usual. ${ }^{17}$ Moreover, dimensions of craving were not significantly related to $\mathrm{CO}$. This absence of relation highlights the fact that craving cannot be considered as solely the result of a biological measure, such as expired $\mathrm{CO}$ or a potential deficit in nicotine, but as a complex and multidetermined phenomenon that also relies on psychological variables such as expectancies, beliefs, the affective state, and motivation. The multidimensional nature of craving has been developed in the elaborated intrusion theory of desire. ${ }^{4-16}$

Interestingly, Factor 1 (craving related to the relief of withdrawal and/or negative affect), which is closely related to dependence (as measured by the FTND), was the only dimension positively associated with the negative impact of tobacco on daily life, with the frequency of smoking triggered by negative emotional contexts and with the smoking history. In other words, high scores on this dimension characterized more-dependent smokers who reported stronger experience of the negative impact of tobacco, more frequent smoking in response to nega- tive emotional contexts, and a longer smoking history. In contrast, Factor 2 (intention and desire to smoke), was less related to problematic outcomes (eg, no relation with negative impact in the daily life, relations of smaller amplitudes with dependence symptoms and lack of control). Accordingly, this factor may represent a type of craving, less intense and more focused on positive reinforcement (as reflected by items 3 and 8), likely to be experienced by smokers with low dependence levels and who initiated smoking more recently.

It is worth noting that in contrast with analyses realized on the English version of the QSU and consistent with those related to the French version, item 9 ("I have an urge for a cigarette") loaded on Factor 1. This is due to an inaccurate translation of this item by Guillin et $\mathrm{al}^{27}$ when they developed the French QSU. Indeed, the word "urge" has been translated in French in a way that suggests an "urgent need" rather than a "strong desire". Thus, the words used in this translation seem more closely related to the anticipation of relief of discomfort as compared with the words used in the English version that are more tightly related to the anticipation of positive outcomes.

A first limitation to this study is that no information was collected regarding the potential motivation for smoking cessation and previous quit attempts. In the same vein, we did not collect any information regarding potential comorbid psychiatric disorders (eg, alcohol-dependence, pathological gambling, anxiety), thereby limiting the generalizability of the present findings. A second limitation is that our sample was composed of relatively low smokers (with regard to the FTND score). However, our results suggest that the more the participants have high FTND scores, the more the experience elevated levels of craving, especially on the relief from negative affect dimension. Our study might thus underestimate mechanisms that are more inherent to high levels of craving. A third limitation is that three items exhibit loadings lower than 0.40. Even if the suppression of those items did not lead to any important change in the present sample, future studies should further examine whether these items provide enough information. One interesting way would be the use, among a new sample of smokers, of an item-analysis approach modeling the probability of a specified item's response through logistic functions of the difference between the person and item parameters, such as those mathematical approaches derived from Rash mode ${ }^{59}$ or artificial neural networks. ${ }^{60}$ Finally, we did not manipulate the time lag between the last cigarette and the completion of the questionnaires. This would have allowed capturing the 
transient and changing nature of craving across time. ${ }^{12,61}$ Future studies should further examine this question.

On the whole, the current study showed that the QSU-12 is a useful instrument for assessing the multidimensional construct of cigarette craving. The time saved thanks to the item-number reduction improves the clinical and research feasibility of this tool.

\section{Acknowledgments}

The authors thank Arnaud Carré and all the members of the Groupe de Réflexion en Psychopathologie Cognitive (GREPACO) for their help in disseminating the study protocol. We would also like to thank Melissa Morales-Duarte for her help in data collection and the members of the Laboratory for Experimental Psychopathology for their useful comments on a preliminary draft of the article.

\section{Disclosure}

This work has been partly supported by Université catholique de Louvain (Belgium) and by a grant (grant number FC 78142) from the Belgian National Fund for Scientific Research (awarded to Alexandre Heeren). These funding bodies did not exert any editorial direction or censorship on any part of this article. All authors report no competing financial interests or potential conflicts of interest, and no financial relationships with commercial interests. The authors report no other conflicts of interest in this work.

\section{References}

1. World Health Organization. The ICD-10 Classification of Mental and Behavioural Disorders: Clinical Descriptions and Diagnostic Guidelines. Geneva, Switzerland: World Health Organization; 1992.

2. American Psychiatric Association. Diagnostic and Statistical Manual of Mental Disorders. 5th ed. Washington, DC: American Psyciatric Publishing; 2013.

3. Drummond DC. Theories of drug craving, ancient and modern. Addiction. 2001;96(1):33-46.

4. Kavanagh DJ, Andrade J, May J. Imaginary relish and exquisite torture: the elaborated intrusion theory of desire. Psychol Rev. 2005; 112(2):446-467.

5. Robinson TE, Berridge KC. Incentive-sensitization and addiction. Addiction. 2001;96(1):103-114.

6. Tiffany ST. A cognitive model of drug urges and drug-use behavior: Role of automatic and nonautomatic processes. Psychol Rev. 1990;97(2): $147-168$.

7. Ferguson SG, Shiffman S, Gwaltney CJ. Does reducing withdrawal severity mediate nicotine patch efficacy? A randomized clinical trial. J Consult Clin Psychol. 2006;74(6):1153-1161.

8. Killen JD, Fortmann SP. Craving is associated with smoking relapse: findings from three prospective studies. Exp Clin Psychopharmacol. 1997;5(2):137-142.

9. Shiffman S, Engberg JB, Paty JA, et al. A day at a time: predicting smoking lapse from daily urge. J Abnorm Psychol. 1997;106(1):104-116.

10. Franklin T, Wang Z, Suh JJ, et al. Effects of varenicline on smoking cue-triggered neural and craving responses. Arch Gen Psychiatry. 2011;68(5):516-526.
11. Hartwell KJ, Lematty T, McRae-Clark AL, Gray KM, George MS, Brady KT. Resisting the urge to smoke and craving during a smoking quit attempt on varenicline: results from a pilot fMRI study. Am J Drug Alcohol Abuse. 2013;39(2):92-98.

12. Tiffany ST, Wray JM. The clinical significance of drug craving. Ann N Y Acad Sci. 2012;1248:1-17.

13. Brandon TH, Wetter DW, Baker TB. Affect, expectancies, urges, and smoking: do they conform to models of drug motivation and relapse? Exp Clin Psychopharmacol. 1996;4(1):29-36.

14. Kozlowski LT, Wilkinson DA. Use and misuse of the concept of craving by alcohol, tobacco, and drug researchers. Br J Addict. 1987;82(1): $31-45$.

15. Cepeda-Benito A, Henry K, Gleaves DH, Fernandez MC. Cross-cultural investigation of the Questionnaire of Smoking Urges in American and Spanish smokers. Assessment. 2004;11(2):152-159.

16. May J, Andrade J, Panabokke N, Kavanagh D. Images of desire: cognitive models of craving. Memory. 2004;12(4):447-461.

17. Tiffany ST, Drobes DJ. The development and initial validation of a questionnaire on smoking urges. Br J Addict. 1991;86(11):1467-1476.

18. Dawkins L, Powell JH, West R, Powell J, Pickering A. A double-blind placebo controlled experimental study of nicotine: I - effects on incentive motivation. Psychopharmacology (Berl). 2006;189(3):355-367.

19. Haasova M, Warren FC, Ussher M, et al. The acute effects of physical activity on cigarette cravings: systematic review and meta-analysis with individual participant data. Addiction. 2013;108(1):26-37.

20. Janse Van Rensburg K, Taylor A, Benattayallah A, Hodgson T. The effects of exercise on cigarette cravings and brain activation in response to smoking-related images. Psychopharmacology (Berl). 2012;221(4): 659-666.

21. Ussher M, Aveyard P, Manyonda I, et al. Physical activity as an aid to smoking cessation during pregnancy (LEAP) trial: study protocol for a randomized controlled trial. Trials. 2012;13:186.

22. Rosenberg H. Clinical and laboratory assessment of the subjective experience of drug craving. Clin Psychol Rev. 2009;29(6): 519-534.

23. Davies GM, Willner P, Morgan MJ. Smoking-related cues elicit craving in tobacco "chippers": a replication and validation of the two-factor structure of the Questionnaire of Smoking Urges. Psychopharmacology (Berl). 2000;152(3):334-342.

24. Weinberger AH, Reutenauer EL, Allen TM, et al. Reliability of the Fagerström Test for Nicotine Dependence, Minnesota Nicotine Withdrawal Scale, and Tiffany Questionnaire for Smoking Urges in smokers with and without schizophrenia. Drug Alcohol Depend. 2007; 86(2-3):278-282.

25. Cepeda-Benito A, Reig-Ferrer A. Development of a brief questionnaire of smoking urges - Spanish. Psychol Assess. 2004;16(4):402-407.

26. Müller V, Mucha RF, Ackermann K, Pauli P. Die erfassung des cravings bei rauchern mit einer deutschen version des "Questionnaire on smoking urges" (QSU-G) [The assessment of craving in smokers with a German version of the "Questionnaire on Smoking Urges" (QSU-G)]. Z Klin Psychol Psychother. 2001;30(3):164-171. German.

27. Guillin O, Krebs MO, Bourdel MC, Olie JP, Loo H, Poirier MF. [Validation of the French translation and factorial structure of the Tiffany and Drobes Smoking Urge Questionnaire]. L'Encephale. 1999;26(6):27-31. French.

28. Kozlowski LT, Pillitteri JL, Sweeney CT, Whitfield KE, Graham JW. Asking questions about urges or cravings for cigarettes. Psychol Addict Behav. 1996;10(4):248-260.

29. Cox LS, Tiffany ST, Christen AG. Evaluation of the brief questionnaire of smoking urges (QSU-brief) in laboratory and clinical settings. Nicotine Tob Res. 2001;3(1):7-16.

30. Cappelleri JC, Bushmakin AG, Baker CL, Merikle E, Olufade AO, Gilbert DG. Multivariate framework of the Brief Questionnaire of Smoking Urges. Drug Alcohol Depend. 2007;90(2-3):234-242.

31. Clausius RL, Krebill R, Mayo MS, et al. Evaluation of the brief questionnaire of smoking urges in Black light smokers. Nicotine Tob Res. 2012;14(9):1110-1114. 
32. Toll BA, Katulak NA, McKee SA. Investigating the factor structure of the Questionnaire on Smoking Urges-Brief(QSU-Brief). Addict Behav. 2006;31(7):1231-1239.

33. Toll BA, McKee SA, Krishnan-Sarin S, O'malley SS. Revisiting the factor structure of the questionnaire on smoking urges. Psychol Assess. 2004;16(4):391-395.

34. Araujo RB, Oliveira MDS, Moraes JFD, Pedroso RS, Port F, De Castro MDGTD. Validação da versão brasileira do Questionnaire of Smoking Urges-Brief [Validation of the Brazilian version of Questionnaire of Smoking Urges-Brief]. Revista de Psiquiatria Clinica. 2007;34(4): 166-175. Portuguese.

35. Teneggi V, Oprandi N, Milleri S, et al. Verifica della validità esteriore e del contenuto della versione italiana di tre questionari su craving e astinenza da fumo di sigarette [Assessment of face and content validity of the Italian version of three questionnaires on cigarette smoke craving and withdrawal]. Giornale di Psicopatologia. 2001;7(4):378-386. Italian.

36. Yu X, Xiao D, Li B, et al. Evaluation of the Chinese versions of the Minnesota nicotine withdrawal scale and the questionnaire on smoking urges-brief. Nicotine Tob Res. 2010;12(6):630-634.

37. Berlin I, Singleton EG. Nicotine dependence and urge to smoke predict negative health symptoms in smokers. Prev Med. 2008;47(4): 447-451.

38. Billieux J, Gay P, Rochat L, Khazaal Y, Zullino D, Van der Linden M. Lack of inhibitory control predicts cigarette smoking dependence: evidence from a non-deprived sample of light to moderate smokers. Drug Alcohol Depend. 2010;112(1-2):164-167.

39. Billieux J, Van der Linden M, Ceschi G. Which dimensions of impulsivity are related to cigarette craving? Addict Behav. 2007;32(6): 1189-1199.

40. Fabrigar LR, Wegener DT, MacCallum RC, Strahan EJ. Evaluating the use of exploratory factor analysis in psychological research. Psychol Methods. 1999;4(3):272-299.

41. Heatherton TF, Kozlowski LT, Frecker RC, Fagerström KO. The Fagerström Test for Nicotine Dependence: a revision of the Fagerström Tolerance Questionnaire. Br J Addict. 1991;86(9):1119-1127.

42. Benowitz NL. The use of biologic fluid samples in assessing tobacco smoke consumption. NIDA Res Monogr. 1983;48:6-26.

43. Byrne BM. Structural Equation Modeling with EQS and EQS/Windows. Thousand Oaks, CA: Sage Publications, Inc.; 1994.

44. Mardia KV. Applications of some measures of multivariate skewness and kurtosis in testing normality and robustness studies. Sankhyā: The Indian Journal of Statistics. 1974;36(Series B, Pt 2):115-128.

45. McDonald RP, Ho MH. Principles and practice in reporting structural equation analyses. Psychol Methods. 2002;7(1):64-82.
46. Heeren A, Douilliez C, Peschard V, Debrauwere L, Philippot P. Validité transculturelle du Five Facets Mindfulness Questionnaire: adaptation et validation auprès d'un échantillon francophone [Cross-cultural consistency of the Five Facets Mindfulness Questionnaire: adaptation and validation in a French-speaking sample]. Revue Européenne de Psychologie Appliquée. 2011;61(3):147-151. French.

47. Browne MW. Covariance structures. In: Hawkins DM, editor. Topics in Applied Multivariate Analysis. Cambridge, UK: Cambridge University Press; 1982:72-141.

48. Jöreskog KG, Sörbom D. LISREL 7: A Guide to the Program and Applications. 2nd ed. Chicago, IL: SPSS Inc; 1989.

49. Hoyle RH, Panter AT. Writing about structural equation models. In: Hoyle RH, editor. Structural Equation Modeling: Concepts, Issues, and Applications. Thousand Oaks, CA: Sage Publications, Inc.; 1995: 158-176.

50. Marsh HW, Balla JR, McDonald RP. Goodness-of-fit indices in confirmatory factor analysis: the effects of sample size. Psychol Bull. 1988;103(3):391-410.

51. Cole DA. Utility of confirmatory factor analysis in test validation research. J Consult Clin Psychol. 1987;55(4):584-594.

52. James CR, Mulaik SA, Brett JM. Causal Analysis: Assumptions, Models and Data. Beverley Hills, CA: Sage Publications, Inc.; 1982.

53. Blunch NJ. Introduction to Structural Equation Modeling Using SPSS and AMOS. London, UK: Sage Publications, Ltd.; 2008.

54. Akaike H. Factor analysis and AIC. Psychometrika. 1987;52: 317-332.

55. Browne MW, Cudeck R. Single sample cross-validation indices for covariance structures. Multivariate Behav Res. 1989;24(4):445-455.

56. Nunnally JC. Psychometric Theory. 2nd ed. New York, NY: McGrawHill, Inc; 1978.

57. Steiger JH. Tests for comparing elements of a correlation matrix. Psychol Bull. 1980;87(2):245-251.

58. Smith GT, McCarthy DM, Anderson KG. On the sins of short-form development. Psychol Assess. 2000;12(1):102-111.

59. Rasch G. Probabilistic Models for Some Intelligence and Attainment Tests. Expanded ed. Chicago, IL: The University of Chigago Press; 1980.

60. Shu Z, Henson R, Willse J. Using neural network analysis to define methods of DINA model estimation for small sample sizes. J Classif. 2013;30(2):173-194.

61. Tiffany ST, Warthen MW, Goedeker KC. The functional significance of craving in nicotine dependence. Nebr Symp Motiv. 2009;55:171-197. 


\section{Supplementary material}

Table SI QSU- 12 items

\begin{tabular}{ll}
\hline Item & Factor \\
\hline I. Nothing would be better than smoking a cigarette right now & $\mathrm{FI}$ \\
2. Smoking would make me less depressed & $\mathrm{FI}$ \\
3. Smoking a cigarette would not be pleasant* & $\mathrm{F} 2$ \\
4. All I want right now is a cigarette & $\mathrm{FI}$ \\
5. Even if it were possible, I probably would not smoke now* & $\mathrm{F} 2$ \\
6. I have no desire for a cigarette right now* & $\mathrm{F} 2$ \\
7. Smoking now would make things seem just perfect & $\mathrm{FI}$ \\
8. A cigarette would not taste good right now* & $\mathrm{F} 2$ \\
9. I have an urge for a cigarette & $\mathrm{FI}$ \\
I0. I could control things better if I could smoke right now & $\mathrm{FI}$ \\
II. I am going to smoke as soon as possible & $\mathrm{F} 2$ \\
I2. I would do almost anything for a cigarette right now & $\mathrm{FI}$ \\
\hline
\end{tabular}

Notes: The French translation of these items can be obtained on request by mail or on the website of the Laboratory for Experimental Psychopathology: http://uclep.be. *Reversed items.

Abbreviations: FI, Factor I: relief of negative affect; F2, Factor 2: intention and desire to smoke; QSU-12, 12-item version of the Questionnaire on Smoking Urges.

\section{Publish your work in this journal}

Neuropsychiatric Disease and Treatment is an international, peerreviewed journal of clinical therapeutics and pharmacology focusing on concise rapid reporting of clinical or pre-clinical studies on a range of neuropsychiatric and neurological disorders. This journal is indexed on PubMed Central, the 'PsycINFO' database and CAS, and is the official journal of The International Neuropsychiatric Association (INA). The manuscript management system is completely online and includes a very quick and fair peer-review system, which is all easy to use. Visit http://www.dovepress.com/testimonials.php to read real quotes from published authors.

\footnotetext{
Submit your manuscript here: http://www.dovepress.com/neuropsychiatric-disease-and-treatment-journal
} 